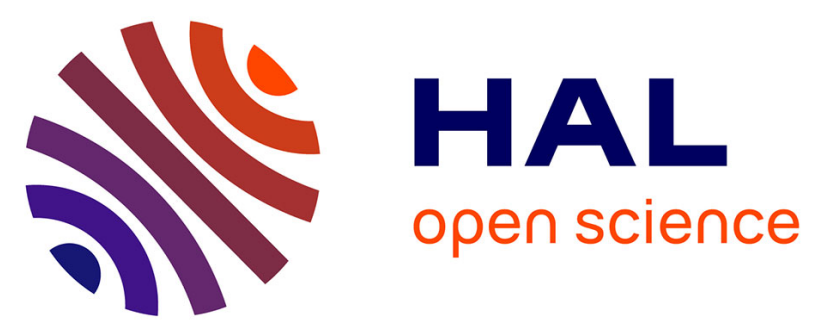

\title{
Advanced Signal Processing Techniques for Fault Detection and Diagnosis in a Wind Turbine Induction Generator Drive Train: A Comparative Study
}

E. El Ahmar, Vincent V. Choqueuse, Mohamed Benbouzid, Yassine Amirat, Joseph El Assad, R. Karam, Said Farah

\section{To cite this version:}

E. El Ahmar, Vincent V. Choqueuse, Mohamed Benbouzid, Yassine Amirat, Joseph El Assad, et al.. Advanced Signal Processing Techniques for Fault Detection and Diagnosis in a Wind Turbine Induction Generator Drive Train: A Comparative Study. IEEE Energy Conversion Congress and Exposition (ECCE), 2010, Sep 2010, Atlanta, United States. pp.3576 - 3581, 10.1109/ECCE.2010.5617914 . hal-00532625

\section{HAL Id: hal-00532625 \\ https://hal.science/hal-00532625}

Submitted on 5 Nov 2010

HAL is a multi-disciplinary open access archive for the deposit and dissemination of scientific research documents, whether they are published or not. The documents may come from teaching and research institutions in France or abroad, or from public or private research centers.
L'archive ouverte pluridisciplinaire HAL, est destinée au dépôt et à la diffusion de documents scientifiques de niveau recherche, publiés ou non, émanant des établissements d'enseignement et de recherche français ou étrangers, des laboratoires publics ou privés. 


\title{
Advanced Signal Processing Techniques for Fault Detection and Diagnosis in a Wind Turbine Induction Generator Drive Train: A Comparative Study
}

\author{
E. Al Ahmar, V. Choqueuse, M.E.H. Benbouzid, Y. Amirat, J. El Assad, R. Karam, and S. Farah
}

\begin{abstract}
This paper deals with the diagnosis of Wind Turbines based on generator current analysis. It provides a comparative study between traditional signal processing methods, such as periodograms, with more sophisticated approaches. Performances of these techniques are assessed through simulation experiments and compared for several types of fault, including air-gap eccentricities, broken rotor bars and bearing damages.
\end{abstract}

Index Terms-Wind turbines, motor current signature analysis, time-frequency signal processing methods, wavelet analysis, failure diagnosis.

\section{INTRODUCTION}

Due to environmental considerations and to the exhaustion of fossil resources, renewable energy sources are gaining more and more importance these days. Since 2004, many indicators of the development of renewable energy have been constantly rising. For example, since 2004, annual renewable energy investment has increased fourfold to reach $\$ 120$ billion in 2008 [1]. Wind power has a major share in this increase since, from 2004 to 2008, wind power capacity increased by $250 \%$ to attend a value of $121 \mathrm{GW}$ (see Fig.1 [1]). Due to different factors, such as wind speed and acoustic noise, wind parks are being mainly constructed offshore. Studies shows that offshore wind power produced $1873 \mathrm{MW}$ in Europe. To increase this production, 11 parks are currently under construction and 26 parks are in project (see table I). Due to the difficulties of maintenance in offshore environment, teledetection of wind turbine faults is becoming a crucial issue. Different methods of fault detection exist. These include monitoring of the acoustic vibration, internal and external temperature, stator voltages and/or currents. Although thermal and vibration monitoring have been utilized for decades, most of the recent research has been directed toward electrical monitoring, with emphasis on the generator stator current. In this study, the generator stator

E. Al Ahmar, V. Choqueuse, M.E.H. Benbouzid, and Y. Amirat are with the Laboratoire Brestois de Mcanique et des Systmes (LBMS EA 4325), University of Brest, Rue de Kergoat, CS 93837, 29238 Brest Cedex 03, France (e-mail: Elie.Alahmar@univ-brest.fr,vincent.choqueuse@univ-brest.fr m.benbouzid@ieee.org). Elie Al-Ahmar, J. El-Assad, R. Karam and S. Farah are with the Faculty of Sciences and Computer Engineering, Holy Spiri University of Kaslik, BP 446, Jounieh, Lebanon.

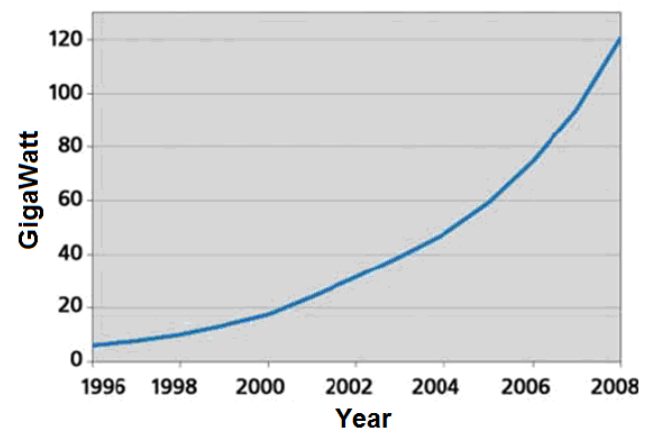

Fig. 1. Annual wind power in the world between years 1996 and 2008.

TABLE I

Wind Power Produced OfFshore in Europe [1] [4].

\begin{tabular}{|c|c|c|c|}
\hline & Operational & Construction & Project \\
\hline $\begin{array}{c}\text { Number } \\
\text { of parks }\end{array}$ & 28 & 11 & 26 \\
\hline $\begin{array}{c}\text { Produced } \\
\text { Power (MW) }\end{array}$ & 1873 & 2743 & 5716 \\
\hline
\end{tabular}

current is analyzed through signal processing tools for fault detection [2], [3]. The performances of several signal processing tools for the detection of air-gap eccentricity, broken rotor bars and bearing damages are compared. This paper is organized as follows. Section II presents the considered faults, section III describes the employed signal processing techniques and section IV provides an experimental comparison of these methods.

\section{Major FAults StUdied}

Wind turbine is a complex mechanical system. Its major components are presented in Fig. 2. Faults can occur almost anywhere in this system; examples of mechanical faults range from a bent shaft, which results in a rub between the rotor and stator, to a shorted rotor winding or gearbox failures. This paper focuses on faults that leads to air-gap eccentricities, broken rotor bars and bearing damages.

\section{A. Air gap eccentricity}

Eccentricity faults in electrical machines are caused by an unequal air gap between the stator and rotor [5]-[7]. When 


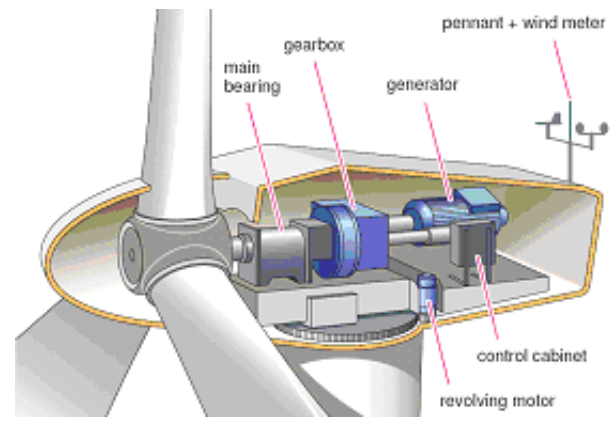

Fig. 2. Wind turbine nacelle cross-section.

this air gap increases the unbalanced magnetic pull or radial forces can cause the stator and rotor rubbing, which may result in major damage in both the stator and the rotor. Two types of eccentricity exist or even tend to coexist with each others. The first is the static eccentricity where the minimal radial air gap length is fixed in space. It may be caused by an oval shape of the stator core or by a misalignment of the stator and rotor. Dynamic eccentricity, on the other hand, is caused by a difference between the center of the rotor and the center of rotation which may be caused by a bent rotor shaft or a bearing fault, etc. both these eccentricities cause a rub between the stator and the rotor causing critical damage in both of them which may lead to a total breakdown of the machine. In order to detect these eccentricity faults, two methods exist. The first one consists of monitoring the behavior of the current at the sidebands of the slot frequencies. The main drawback of this approach relies on the fact that it requires knowledge of the intimate details of the machine's anatomy [8]. The second method is based on the monitoring of the current at the fundamental sidebands of the supply frequency. Frequencies of interest are located at $f_{e c c}$ given by the following equation [8]:

$$
f_{e c c}=f_{s}\left[1 \pm m\left(\frac{1-s}{p}\right)\right]
$$

where $f_{s}$ is the electrical supply frequency, $s$ is the per-unit slip, $p$ is the number of poles and $m \in \mathbb{N}$.

\section{B. Broken rotor Bars}

Though several types of rotor cages exist, most wind turbines have cast rotors. In this case, damage of a rotor bar is fatal since it cannot be repaired. Broken rotor bars can be caused by thermal, magnetic, environmental or mechanical stresses [9]. When a rotor bar breaks in the rotor cage, it induces magnetic anomalies which produce harmonic frequencies in the current spectrum at frequencies $f_{b r b}$ [9]:

$$
f_{b r b}=f_{s}\left[k\left(\frac{1-s}{p}\right) \pm s\right]
$$

where $k / p=1,3,5,7,11,13$.

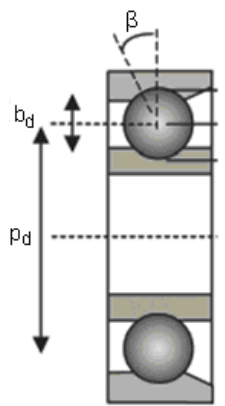

Fig. 3. Mechanical representation of bearings.

\section{Bearing Damage}

Most of rotating mechanical systems contains one or many bearings to insure smooth rotation with minimal losses. Bearings consist of an inner ring and external one, between which rotates a number of balls (see Fig.3). Bearing may be damaged by sudden load variations or rotor-stator misalignments. Bearing faults are the most common fault in wind turbines (40-50\%). Vibrations associated with bearing faults reflect themselves in the current spectrum at frequencies [9]:

$$
f_{b n g}=\left|f_{s} \pm m f_{v}\right|
$$

where $m \in \mathbb{N}$ and $f_{v}$ depends on bearing fault. Bearing faults include

- Faults caused by an outer bearing race defect where:

$$
f_{v}=\frac{\alpha f_{r}}{2}\left[1-\frac{b_{d}}{p_{d}} \cos (\beta)\right]
$$

- Faults caused by an inner bearing race defect where:

$$
f_{v}=\frac{\alpha f_{r}}{2}\left[1+\frac{b_{d}}{p_{d}} \cos (\beta)\right]
$$

- Faults caused by a ball defect where:

$$
f_{v}=\frac{p_{d} f_{r}}{2 b_{d}}\left[1+\left(\frac{b_{d}}{p_{d}} \cos (\beta)\right)^{2}\right]
$$

- Faults caused by a train defect where frequencies of interest are given by:

$$
f_{v}=\frac{f_{r}}{2}\left[1-\frac{b_{d}}{p_{d}} \cos (\beta)\right]
$$

where $f_{r}$ is the rotational frequency, $\alpha$ is the number of balls, $b_{d}$ and $d_{p}$ are respectively the ball diameter and the bearing pitch diameter (see Fig.2) and $\beta$ is the contact angle of the ball.

\section{Advanced Signal Processing Techniques}

This section presents different signal processing technique which can be employed to extract the frequency content of a discrete signal. In this following, the current will be denoted by the discrete signal $x[n]$, which is obtained by sampling the continuous time current every $T_{s}=1 / F_{s}$ seconds. 


\section{A. Periodogram}

The periodogram, $P_{x}(f)$, estimates the Power Spectral Density (PSD) of a signal $x[n]$. It is given by [10]:

$$
P_{x}(f)=\frac{|X(f)|^{2}}{N}
$$

where $X(f)$ is the Discrete Fourier Transform of $x[n]$ i.e.

$$
X(f)=\sum_{n=0}^{N-1} x[n] e^{-2 j \pi f n / F_{s}}
$$

where $F_{s}$ is the sampling frequency. In practice, (9) is evaluated through a Fast Fourier Transform (FFT) [10], which reduces the number of computations to $\mathcal{O}(N \log (N))$ operations. One should note The periodogram is not a consistent estimator of the PSD since it has a non-zero biais and its variance does not tend to zero as the data length $N$ tends to infinity. Despite of this drawback, the periodogram has been used extensively for failure detection in the literature [8].

\section{B. Welch Periodogram}

As compared to the classical periodogram, Welch periodogram is an improved estimator of the PSD that reduces both the variance and the biais. The Welch method divides $x[n]$ into segments, computes a modified periodogram of each segment and then averages the result. The Welch periodogram, $P_{w}(f)$, can be expressed into a mathematical form as [10]:

$$
P_{w}(f)=\frac{1}{L} \sum_{k=1}^{k=L} P_{x w}^{(k)}(f)
$$

where:

$$
P_{x w}^{(k)}(f)=\frac{\left|X_{x w}^{(k)}(f)\right|^{2}}{N U}
$$

and where $U$ is a normalization factor. Furthermore, $X_{w}^{(k)}(f)$ corresponds to the DFT of the windowed signal $x[n] w\left[n-\tau_{k}\right]$, where $w[$.$] is a time-window (hanning, hamming, kaiser) and$ where $\tau_{k}$ is a time lag.

\section{Spectrogram}

To obtain the evolution of the frequency content over time, Fourier transforms can be computed for different time segments and then arranged one next to the other over the time axis. This method is known as the Short Time Fourier Transform (STFT). For discrete signals, the STFT is given by [11]

$$
S T F T[f, \tau]=\sum_{n=0}^{N-1} x[n] w[n-\tau] e^{-2 j \pi f n / F_{e}}
$$

where $w[$.$] is a time window. The spectrogram is defined as$ the square modulus of the STFT i.e. $|S T F T[f, \tau]|^{2}$. The time and frequency resolution is limited by the Heisenberg-Gabor inequality [11]. In the case of the spectrogram, this resolution is the same for all time-frequency bins. One should note that the spectrogram have been used previously in [12], [13] for diagnosis purpose in time-varying condition.

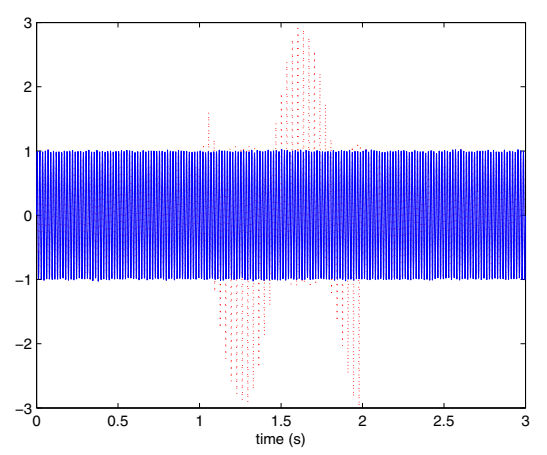

Fig. 4. Simulation of the current of a healthy machine in blue and of a machine with an eccentricity problem between $1.024 \mathrm{~s}$ and $2.024 \mathrm{~s}$.

\section{Scalogram}

Wavelet Transform (WT) provides a time-scale (or timefrequency) representation of a signal. While STFT gives constant time-frequency resolution, WT is a multi-resolution technique which analyses frequencies with different resolutions. The WT gives a good time resolution and poor frequency resolution at high frequencies, and provides good frequency resolution and poor time resolution at low frequencies [14]. The Wavelet Transform at frequency scale $l$ is given by:

$$
W\left(a^{l}, \tau\right)=\sum_{n=0}^{N-1} x[n] \psi_{l}^{*}[n-\tau]
$$

where

$$
\psi_{l}[n]=\frac{1}{\sqrt{a^{l}}} \psi\left(\frac{n}{a^{l}}\right)
$$

and where $\psi($.$) is the mother wavelet which satisfies a number$ of conditions. The scalogram is defined as the square modulus of the WT i.e. $\left|W\left(a^{l}, \tau\right)\right|^{2}$. One should note that the Wavelet Transform have been used previously in [15]-[17] for failure detection.

\section{Simulation Results}

The focus of this section is to find which signal processing method is the most suitable for the detection of each mechanical fault. In this section, the simulated signal $x[n]$ is given by:

$$
x[n]=\sin \left(2 \pi f_{s} n / F_{s}\right)+e[n]+b[n]
$$

where $F_{s}=1000 \mathrm{~Hz}, e[n]$ depends on the fault and $b[n]$ is a gaussian noise with zero mean and a variance equals to $\sigma^{2}=10^{-4}$ i.e. $b[n] \sim \mathcal{N}\left(0,10^{-4}\right)$. For all simulations, an hamming window $w[n]$ have been used for the Welch periodogram and the spectrogram. For the Welch periodogram, eight sections of equal length, each with $50 \%$ overlap, have been extracted before averaging. Finally, the length of the spectrogram window, $w[$.$] , have been fixed to 256$ samples and the mother wavelet of the scalogram was a Mexican hat. 


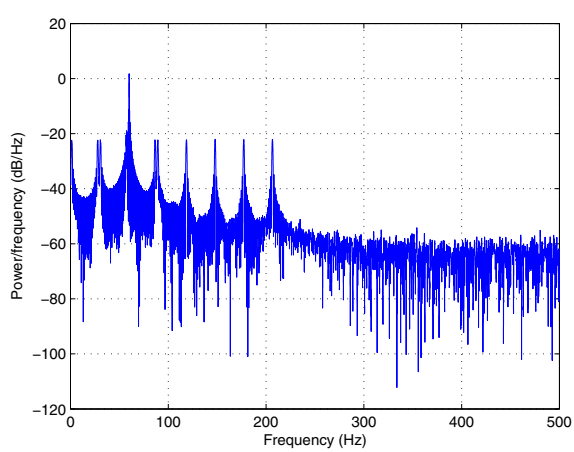

Fig. 5. Periodogram of the monitored current in the case of an eccentricity fault between $1.024 \mathrm{~s}$ and $2.024 \mathrm{~s}$.

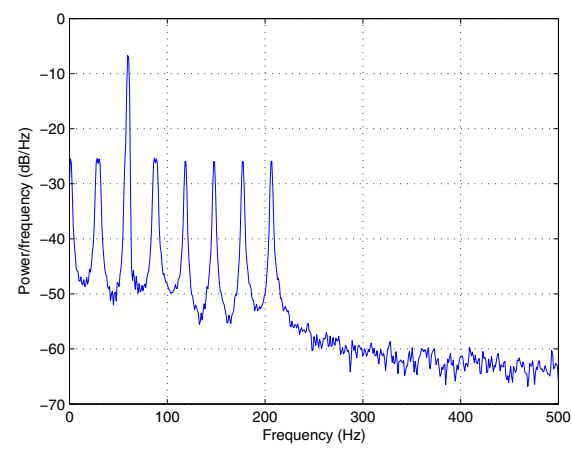

Fig. 6. Welch periodogram of the monitored current in the case of an eccentricity fault between $1.024 \mathrm{~s}$ s and $2.024 \mathrm{~s}$.

\section{A. Air-gap eccentricity}

In this subsection, air gap eccentricity faults are simulated by generating an additive signal $e[n]$, whose spectral components are given by (1). The parameters are fixed to $s=0.033, p=2, m=[1, \cdots, 5]$ and the eccentricity fault is simulated between $1.024 \mathrm{~s}$ and $2.024 \mathrm{~s}$ (see Fig. 4). The first signal processing method applied to these signals is the periodogram (see Fig. 5). The five harmonics ( $m=[1, \cdots, 5]$ ), corresponding to the fault are theoretically equal to $89.01 \mathrm{~Hz}$, $118.02 \mathrm{~Hz}, 147.03 \mathrm{~Hz}, 176.04 \mathrm{~Hz}$ and $205.5 \mathrm{~Hz}$. Using the classical periodogram technique, these frequencies are estimated at $89.43 \mathrm{~Hz}, 118.7 \mathrm{~Hz}, 148 \mathrm{~Hz}, 177.3 \mathrm{~Hz}$ and $206.6 \mathrm{~Hz}$ respectively. The same results are obtained with the Welch periodogram (see Fig. 6). Figures 7 and 8 display the spectrogram and the scalogram respectively. On can observe that these methods bring new information that could not be extracted with the previous periodograms. Furthermore, one can note that the scalogram has advantages over the spectrogram since it provides a multiresolution analysis of the signal.

\section{B. Broken rotor bars}

The second fault studied is a broken rotor bar fault. Its signature is given by equation (2). Figures 9 and 10 show the classical and Welch periodogram of the current in the case of

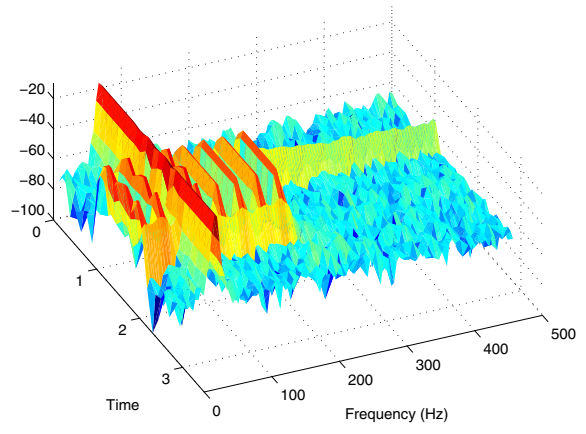

Fig. 7. Spectrogram of the monitored current in the case of an eccentricity fault between $1.024 \mathrm{~s}$ and $2.024 \mathrm{~s}$.

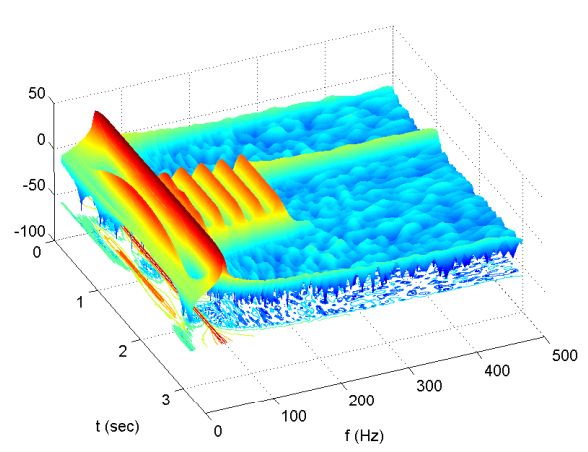

Fig. 8. Scalogram of the monitored current in the case of an eccentricity fault between $1.024 \mathrm{~s}$ and $2.024 \mathrm{~s}$.

TABLE II

HARMonics Detected in The CASE of A BRoKen Rotor BAR.

\begin{tabular}{|c||c|c|c|c|}
\hline \multicolumn{1}{|c||}{} & \multicolumn{4}{c|}{ harmonics $f_{s}(1-2 s)$} \\
\hline $\mathrm{s}$ & 1 & 2 & 3 & 4 \\
\hline \hline$f_{b r b}$ & $55.98 \mathrm{~Hz}$ & $171.9 \mathrm{~Hz}$ & $287.9 \mathrm{~Hz}$ & $404.2 \mathrm{~Hz}$ \\
\hline Per./Welch & $56.04 \mathrm{~Hz}$ & $172.08 \mathrm{~Hz}$ & $288.12 \mathrm{~Hz}$ & $404.16 \mathrm{~Hz}$ \\
\hline Error & $0.107 \%$ & $0.104 \%$ & $0.076 \%$ & $0.01 \%$ \\
\hline
\end{tabular}

\begin{tabular}{|c||c|c|c|c|}
\hline \multicolumn{1}{|c||}{} & \multicolumn{4}{c|}{ harmonics $f_{s}(1+2 s)$} \\
\hline $\mathrm{s}$ & 1 & 2 & 3 & 4 \\
\hline \hline$f_{b r b}$ & $60 \mathrm{~Hz}$ & $176.04 \mathrm{~Hz}$ & $292.08 \mathrm{~Hz}$ & $408.12 \mathrm{~Hz}$ \\
\hline Per./Welch & $59.98 \mathrm{~Hz}$ & $176.3 \mathrm{~Hz}$ & $292.2 \mathrm{~Hz}$ & $408.2 \mathrm{~Hz}$ \\
\hline Error & $0.033 \%$ & $0.147 \%$ & $0.041 \%$ & $0.019 \%$ \\
\hline
\end{tabular}

a damaged rotor. Table II shows the frequency location of the harmonics associated with the broken bar. The harmonics are detected at the same frequencies for the classical and Welch periodogram. However, as one can observe from Fig. 10, the Welch periodogram presents a better signal to noise ratio. Figures 11 and 12 show the spectrogram and the scalogram, respectively. Despite the fact that this method brings no real amelioration in the spectral resolution, it brings great information on the time occurrence of the fault, which can be exploited for fault discrimination. 


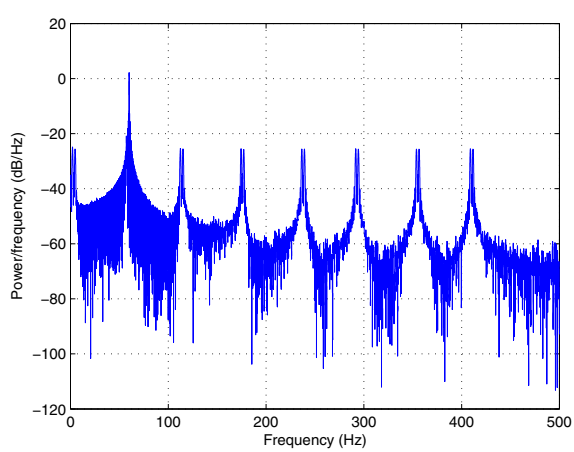

Fig. 9. Periodogram of the monitored current in the case of broken rotor bars between $1.024 \mathrm{~s}$ and $2.024 \mathrm{~s}$.

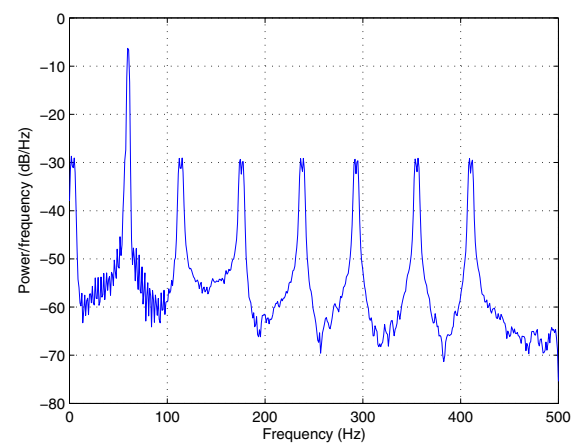

Fig. 10. Welch periodogram of the monitored current in the case of broken rotor bars between $1.024 \mathrm{~s} \mathrm{~s}$ and $2.024 \mathrm{~s}$.

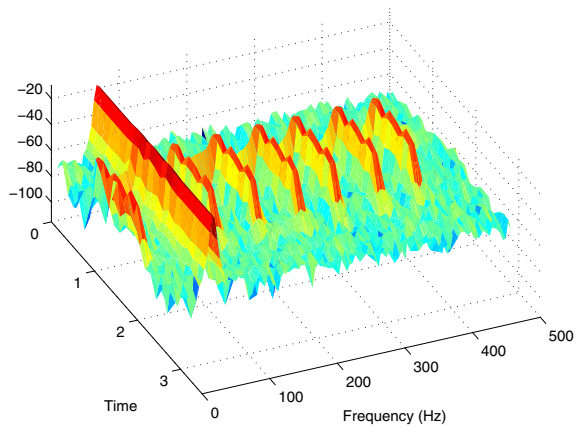

Fig. 11. Spectrogram of the monitored current in the case of broken rotor bars between $1.024 \mathrm{~s}$ and $2.024 \mathrm{~s}$.

\section{Bearing damage}

In wind turbine, bearings faults are the most common fault. In this case, the damage can be caused by different sources such as the outer or the inner rings, the balls or the race. In the following, all these causes are combined together to simulate the worst scenario. The four bearing fault signatures in (4), (5), (6) and (7) are included in the faulty signal. The other simulation parameters are fixed as follows: $m=\{1,2\}, \mathrm{s}=0.033, \mathrm{fr}=29.01 \mathrm{~Hz}, \mathrm{bd}=0.01 \mathrm{~m}, \mathrm{pd}=0.1 \mathrm{~m}, \mathrm{~N}=12$

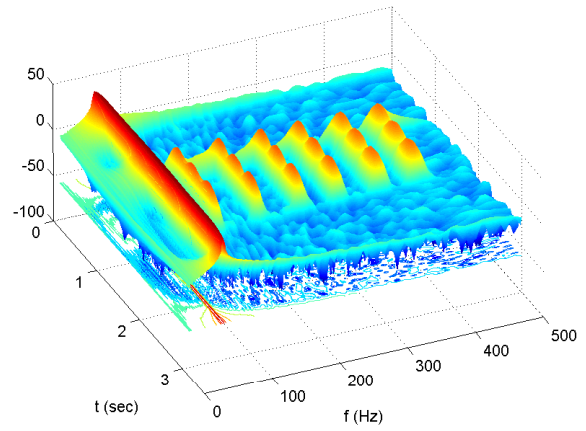

Fig. 12. Scalogram of the monitored current in the case of broken rotor bars between $1.024 \mathrm{~s}$ and $2.024 \mathrm{~s}$.

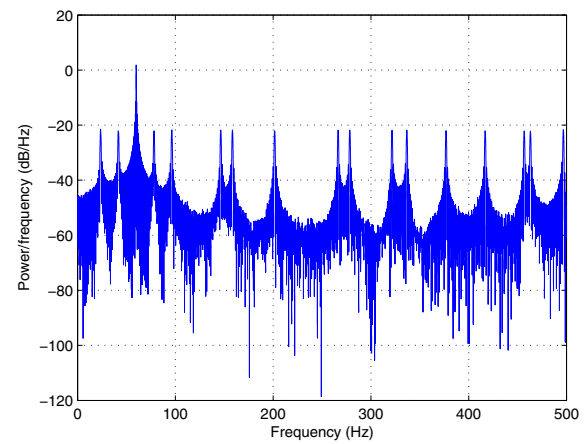

Fig. 13. Periodogram of the monitored current in the case of bearing damages between $1.024 \mathrm{~s}$ and $2.024 \mathrm{~s}$.

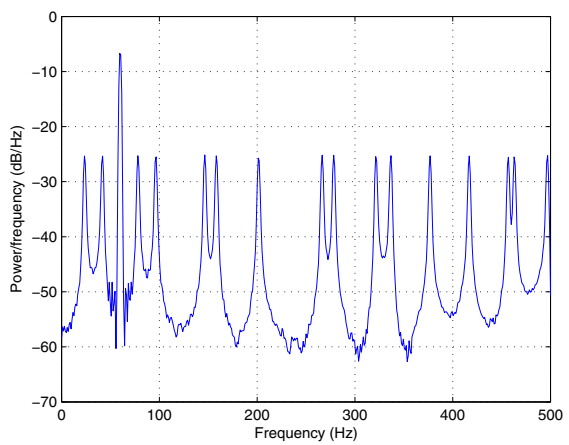

Fig. 14. Welch periodogram of the monitored current in the case of bearing damages between $1.024 \mathrm{~s} \mathrm{~s}$ and $2.024 \mathrm{~s}$.

and $\beta=25^{\circ}$. The periodogram and the Welch periodogram are shown in Fig.13 and 14, respectively. As previously observed, the Welch periodogram leads to a better frequency representation than the classical periodogram in terms of signal to noise ratio. Figures 15 and 16 display the spectrogram and the scalogram of the signal. As previously discussed, the scalogram provides a more natural representation since low-frequency components have high-frequency resolution and high-frequency components have high-time resolution. 


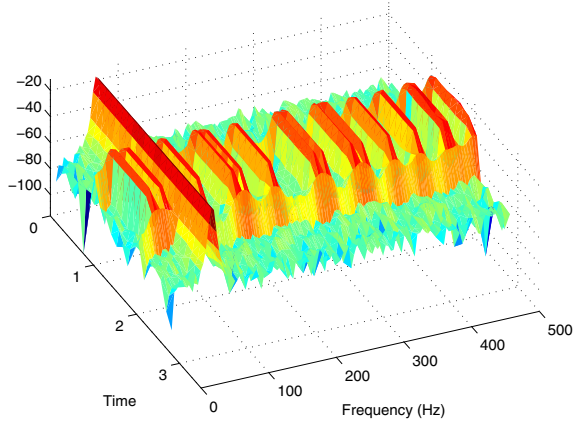

Fig. 15. Spectrogram of the monitored current in the case of bearing damages between $1.024 \mathrm{~s}$ and $2.024 \mathrm{~s}$

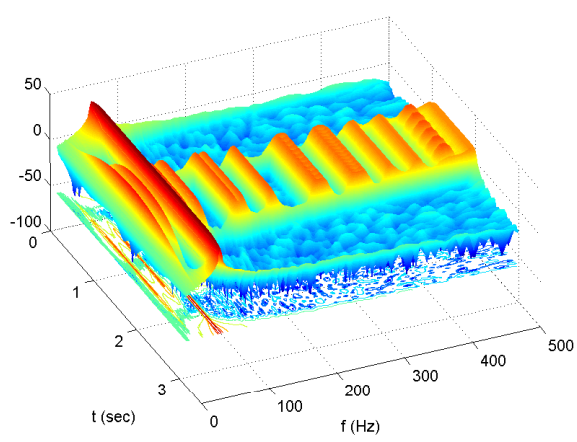

Fig. 16. Scalogram of the monitored current in the case of bearing damages between $1.024 \mathrm{~s}$ and $2.024 \mathrm{~s}$.

\section{CONCLUSION}

This work presented a comparison between four signal processing methods for fault detection in the case of wind turbines. Experimental simulations have shown that the classical and Welch Periodogram have very close performances. However for noisy data, the Welch periodogram exhibits a better signal to noise ratio. As compared to Periodogram and Welch Periodogram, the spectrogram and the scalogram, which are time-frequency representations, bring up major information concerning the time occurrence of the fault. Future works will focus on the evaluation of the presented techniques with experimental signals.

\section{REFERENCES}

[1] "Ren 21: Renewable global status report," 2009, http://www.ren21.net/ pdf/RE_GSR_2009_Update.pdf.

[2] R. Kryter and H. Haynes, "Condition monitoring of machinery using motor current signature analysis," Sound and Vibration Magazine, p. 1421, 1989.

[3] A. Cardoso and S. Saraiva, "Computer-aided detection of airgap eccentricity in operating three-phase induction motors by park's vector approach," IEEE Transactions on Industry Applications, vol. 28, no. 5, pp. 897-901, 1993.

[4] "List of offshore parcs," The Wind Power, Tech. Rep., 2010, http://www. thewindpower.net/29-parcs-offshore.php.

[5] P. Vas, Parameter Estimation, Condition Monitoring, and Diagnosis of Electrical Machines. Oxford Univeristy Press, 1993.

[6] B. Heller and V. Hamata, Harmonic Field Effects in Induction Machine. Elsevier Scientific Publishing Company, 1977.

[7] J. Cameron, W. Thomson, and A. Dow, "Vibration and current monitoring for detecting airgap eccentricity in large induction motors," in IEE Proceedings in Electric Power Applications B, vol. 133, no. 3, 1986, pp. 155-163.

[8] M. Benbouzid, "A review of induction motors signature analysis as a medium for faults detection," IEEE Transactions on Industrial Electronics, vol. 47, no. 5, pp. 984-993, 2000.

[9] S. Nandi, H. Toliyat, and L. Xiaodong, "Condition monitoring and fault diagnosis of electrical motors - a review," IEEE Trans. Energy Conversion, vol. 20, no. 4, pp. 719-729, 2005.

[10] A. Oppenheim, R. Schafer, and W. Padgett, Discrete-Time Signal Processing, 3rd ed. Prentice Hall, 2009.

[11] P. Flandrin, Time-frequency/time-scale analysis. Academoc Press, 1998.

[12] M. Benbouzid and G. Kliman, "What stator current processing based technique to use for induction motor rotor faults diagnosis?" IEEE Transactions on Energy Conversion, vol. 18, no. 2, pp. 238-244, 2003.

[13] J.Cusido, L. Romeral, J. Ortega, J. Rosero, and A. Espinosa, "Fault detection in induction machines using power spectral density in wavelet decomposition," IEEE Transactions on Industrial Electronics, vol. 55, no. 2, pp. 633-643, 2008.

[14] S. Mallat, A Wavelet Tour of Signal Processing: The Sparse Way, 3rd ed. Academic Press, 2008.

[15] H. Douglas, P. Pillay, and A. Ziarani, "A new algorithm for transient motor current signature analysis using wavelet," IEEE Transactions on Industry Applications, vol. 40, no. 5, pp. 1361-1368, 2004.

[16] M. Riera-Guasp, J. Antonio-Daviu, J. Roger-Folch, and M. M. Palomares, "The use of the wavelet approximation signal as a tool for the diagnosis of rotor bar failure," IEEE Transactions on Industry Applications, vol. 44, no. 3, 2008

[17] S. Kia, H. Henao, and G. Capolino, "Diagnosis of broken-bar fault in induction machines using discrete wavelet transform without slip estimation," IEEE Transactions on Industry Applications, vol. 45, no. 4, pp. 1395-1404, 2009. 